\section{Anthropocene: keep the guard up}

Chris Thomas writes that recent gains in species numbers associated with climate warming could more than balance species losses (Nature 502, 7; 2013). But conservation is not just about total species richness - it is also about functioning ecosystems.

Unlike ecosystems that have resulted from millennia of competition and predation, we are much less sure about the stability of new, unfamiliar ones created by invasive species, which we know can wreak havoc.

Thomas also extols the virtues of hybrid vigour generated by crosses between native and immigrant species. But again, we have little idea of these newcomers' long-term future because they have yet to be winnowed by selection - in contrast to their contemporary, non-hybrid counterparts. Furthermore, species hybridization flies in the face of conservation, which aims to preserve extant species and their genomes.

We are still ill-equipped to predict the biological effects of climate change. It would therefore be foolish from the standpoint of both ecology and evolution to stop protecting preAnthropocene ecosystems and species from the onslaught of climate-driven newcomers. Tim Caro University of California, Davis, USA. tmcaro@ucdavis.edu

\section{Anthropocene: action makes sense}

Chris Thomas argues that natural hybridization of invasive and native species could have unforeseen ecological benefits (Nature 502, 7; 2013). However, it is dangerous to underestimate non-native species' potential for ecological and economic damage, which can manifest after decades of remaining innocuous, or in subtle but enormously harmful ways (D. Simberloff et al. Trends Ecol. Evol. 28, 58-66; 2013).

Thomas cites Spartina anglica as a potential contributor to future biodiversity. But this plant is so widespread and destructive that it is on the International Union for the Conservation of Nature's list of ' 100 of the World's Worst Invasive Alien Species'.

Any increase in local biodiversity that might arise from introduced species will be countered by an overall global decrease. Hawaii, for example, once had 114 native bird species: 55 of these are now extinct and 53 have been introduced, so the local change in species number is minimal. Globally, however, the change is a disaster. The introduced species are common elsewhere, but $48 \%$ of the islands native species are gone forever.

The draft European Union legislation for controlling introduced species does not assume that their impact is always negative, as Thomas implies. Species will be riskassessed, and states will then be obliged to control at most 50 of those confirmed to be harmful.

We maintain that combating invading species after gauging the risk they pose is well justified on scientific grounds and is not "irrational".

Daniel Simberloff University of Tennessee, Knoxville, USA.

tebo@utk.edu

Piero Genovesi Institute for Environmental Protection and Research, and IUCN SSC Invasive Species Specialist Group, Rome, Italy.

\section{Climate panel is ripe for examination}

Sociologists of science wish to study the Intergovernmental Panel on Climate Change (IPCC) for the same reason that they want to examine other loci at which scientific knowledge is made - whether in a laboratory, the field, a museum or at a conference. We too approached the IPCC in autumn 2010 with a request to study it from the inside; we too were told 'no' (see Nature 502, 281; 2013).

We therefore had to rely on self-reported accounts. Using document analysis and interviews with lead authors, we analysed how authors navigate the distinction between scientific description and value judgements, for example when offering information pertaining to the definition of 'dangerous climate change'.

The IPCC has become a dominant institution in climate science - in the assessment of knowledge for policy-making, and in how assessment practices alter empirical and computersimulated climate science. Global knowledge assessments such as those undertaken by the IPCC call for carefully documented systematic studies by trained ethnographers.

Let us hope that the IPCC will recognize itself as a legitimate object for scholarly investigation this time around.

Mike Hulme, Martin Mahony King's College London, UK. mike.hulme@kcl.ac.uk

\section{Urban greening needs better data}

Current urban-greening programmes are all too often based on inadequate data (see, for example, C. T. Driscoll et al. BioScience 62, 354-366; 2012), and models for estimating the value of urban vegetation are largely untested. To make substantive progress towards urban sustainability, city managers and researchers need to know where, when, how and which greening programmes are appropriate for urban areas.

Simplified urban-forest models have been widely used to estimate the benefits of scattered planting of trees in city parks and avenues, but these mostly fail to build in estimates of uncertainty or to consider trade-offs and costs. For example, urban forests would be unlikely to reduce atmospheric concentrations of polluting particulates and nitrogen dioxide (H. Setälä et al. Environ. Pollut. 183, 104-112; 2013), and their high pollen density could exacerbate respiratory conditions such as asthma.

We suggest, therefore, that urban-greening strategies should be tailored specifically to their localities. Programmes need to be validated by testing against comparative studies that capture spatial and temporal variability in and among cities. This means that local urban data collection and ecosystem modelling will have to meet the same high standards as those applied to non-urban areas.

Diane E. Pataki* University of Utah, Salt Lake City, USA. diane.pataki@utah.edu ${ }^{*}$ On behalf of 9 co-signatories (see go.nature.com/blzh2i for full list).

\section{Bird vision offers sharp insight}

I find the explosion of interest in the visual system of mice surprising, given that murine eyesight is equivalent to $20 / 2,000$ vision in humans. With their 20/50 vision, pigeons might offer a less "blurry picture" of human 20/20 visual acuity (Nature 502, 156-158; 2013).

Mammals and birds have different brain set-ups, but they both have two, similar visual systems (T. Shimizu and A. N. Bowers Behav. Brain Res. 98, 183-191; 1999). Moreover, pigeons could sidestep the logistical and ethical concerns associated with monkey models of visual processing.

Then there are the untouchables - the birds of prey, which could teach us a thing or two about crystal-clear viewing. The eagle's vision, for example, is widely believed to be about $20 / 4$ in human terms.

Damian Scarf University of Otago, Dunedin, New Zealand. damian@psy.otago.ac.nz 